\title{
Case report of three consecutive lues maligna infections in an HIV-infected patient
}

International Journal of STD \& AIDS 2017, Vol. 28(5) 523-525 (C) The Author(s) 2016 Reprints and permissions: sagepub.co.uk/journalsPermissions.nav DOI: 10.1 I77/09564624I6674I02 journals.sagepub.com/home/std

SAGE

\section{Stefanie Sammet and Rika Draenert}

\begin{abstract}
Lues maligna is a rare presentation of an infection with Treponema pallidum. Here we report three lues maligna infections with severe dermatological manifestations in a single HIV-I infected individual. Despite the start of highly active antiretroviral therapy and a substantial increase in CD4 cell count after the first episode, he developed consecutive episodes. We assume a specific immunological predisposition to react to T. pallidum in this patient.
\end{abstract}

\section{Keywords}

Lues maligna, reinfection, HIV-I, skin manifestation, CD4 cell count, Treponema pallidum

Date received: 23 June 2016; accepted: 22 August 2016

\section{Introduction}

Syphilis infections are frequent among HIV-infected individuals, especially men who have sex with men; however, it seldom presents with lues maligna. This clinical entity represents a rare dermatologic manifestation of secondary syphilis and is also known as 'ulcero-nodular syphilis' or 'malignant syphilis'., Reinfection is a possibility, ${ }^{8}$ however this has not been described in HIV infection. Here we describe an HIV-infected individual who developed malignant syphilis with three consecutive infections.

\section{Case report}

A bisexual man in his $40 \mathrm{~s}$ presented to our infectious diseases outpatient department for skin lesions three times (in 2010, 2012 and 2014). He had been diagnosed with HIV infection in 2003. With each episode, the patient suffered from non-specific symptoms such as headache, malaise and subfebrile temperatures. Striking was a disseminated exanthema presenting with ulcerating nodules (Figure 1(a)) for months. The patient's skin in 2010 (Figure 1(b)) showed multiple disseminated polymorphic lesions all over the body without itchiness. In 2012, the skin lesions were not as many as two years before but the rate of ulceration increased. In 2014 (Figure 1(c)), the skin manifestations were even less but got bigger and more ulcerated. The serological tests proved active syphilis in every case.
Treponema pallidum particle agglutination assays (TPPA) for syphilis were positive (2010: 320,000, 2012: 1.28 million, 2014: 320,000) and rapid plasma reagin (RPR) titre increased (2010: 1:128, 2012: 1:32 and 2014: 1:256). Lumbar puncture was performed and neurosyphilis was excluded. The patient reported promiscuous unprotected sexual contacts in the past.

Each time he was treated with ceftriaxone $2 \mathrm{~g}$ intravenously once daily for three weeks due to the extensive dermatologic manifestation. To prevent a JarischHerxheimer reaction we added oral prednisolone $1 \mathrm{mg} / \mathrm{kg}$ body weight only for the first day of treatment. The non-specific flu-like symptoms disappeared quickly within days. All skin lesions healed, partly with scars within three weeks (Figure 1(d)). RPR titres slowly decreased (to 1:4 after the first episode and to 1:16 after the second episode. The patient did not return to our outpatient department after the treatment of the third episode).

He started highly active antiretroviral therapy (HAART) consisting of raltegravir $400 \mathrm{mg}$ bid,

Medizinische Klinik und Poliklinik IV, Section Infectious Diseases, Klinikum der Universität München, Munich, Germany

\section{Corresponding author:}

Rika Draenert, Section Infectious Diseases, Medizinische Klinik und Poliklinik IV, Klinikum der Universität München, Pettenkoferstr. 8a, 80336 Munich, Germany.

Email: rika.draenert@med.uni-muenchen.de 


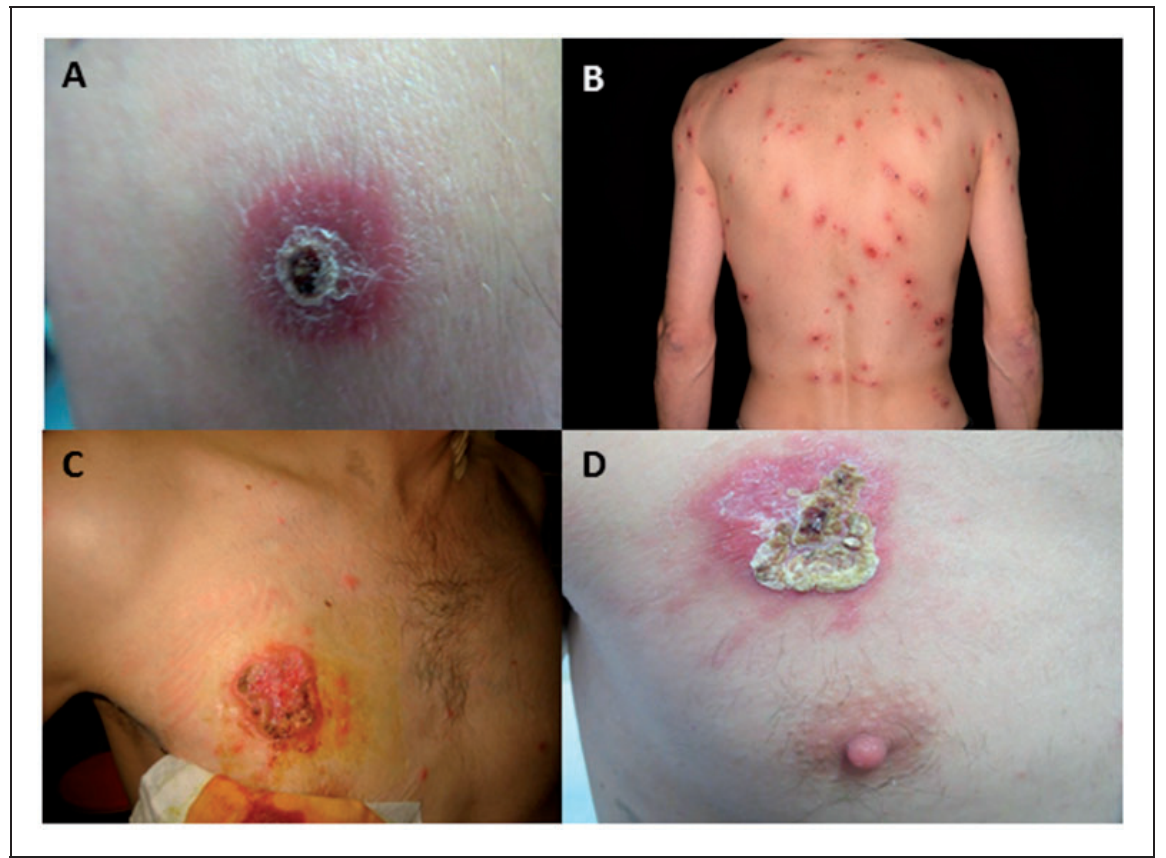

Figure I. Skin manifestations of lues maligna. (a) Typical lesion of lues maligna: papulopustular skin lesion with a lamellar crust (20I0: CD4 count $360 \mu^{-1}$, viral load 3090 copies $/ \mathrm{ml}$ ). (b) Multiple disseminated lesions on the trunk (20l0). (c) $4 \mathrm{~cm} \times 5 \mathrm{~cm}$ ulcero-nodular lesion above the right mamilla (20I4: CD4 count $506 \mu^{-1}$, viral load <50 copies/ml). (d) Same lesion as in (c) seven days after start of ceftriaxone treatment (20I4).

darunavir $800 \mathrm{mg} \mathrm{qd}$, ritonavir $100 \mathrm{mg}$ qd and tenofovir $245 \mathrm{mg}$ qd with the first episode in 2010. His CD4 cell count increased from $360 \mu \mathrm{l}^{-1}(22 \%)$ to $506 \mu \mathrm{l}^{-1}(44 \%)$ and his viral load ranged between $<50$ and 200 copies/ $\mathrm{ml}$ while on HAART. Written informed consent was obtained regarding the publishing of clinical data and images.

\section{Discussion}

Lues maligna is predominantly found in immunodeficient patients such as patients with HIV or AIDS ${ }^{1-6}$ but also occurs in immunocompetent individuals. ${ }^{7}$ The classic lesion of lues maligna is an oval, papulopustular skin lesion with well-demarcated borders sometimes covered with a lamellar crust (Figure 1(a)), but myriad clinical presentations of this disease also exist. Differential diagnosis includes vasculitis, lymphoma, leishmaniasis, pyoderma gangrenosum and varicella zoster infections among others. ${ }^{2}$ Although the clinical manifestations of lues maligna are complicated and severe, the response to antibiotic treatment (benzathine penicillin or ceftriaxone) is excellent. ${ }^{4}$

Interestingly, the patient presented here developed the course of malignant syphilis three times despite the start of HAART after the first episode. As he received adequate antibiotic treatment with ceftriaxone, we assume reinfection for the two following episodes.
To our knowledge, this is the second case reported after the first case report in $1978 .^{8}$ An immunocompromised state, a certain virulent bacterial strain or a unique characteristic of the immune response is discussed as reasons for malignant syphilis., ${ }^{7,8}$ In our patient, the CD4 count improved after HAART start and he had three independent infections which render a virulent strain three times in a row unlikely. Therefore, our hypothesis is that the patient's immune system is predisposed for developing this kind of reaction to Treponema pallidum.

\section{Acknowledgements}

We are indebted to the study participant.

\section{Declaration of conflicting interests}

The authors declared no potential conflicts of interest with respect to the research, authorship, and/or publication of this article.

\section{Funding}

The authors received no financial support for the research, authorship, and/or publication of this article.

\section{References}

1. dos Santos TR, de Castro IJ, Dahia MM, et al. Malignant syphilis in an AIDS patient. Infection 2015; 43: 231-236. 
2. Wang $\mathrm{H}$, Wang $\mathrm{X}$ and Li S. A case of lues maligna in an AIDS patient. Int J STD AIDS 2012; 23: 599-600.

3. Jalili A, Mosleh M, Grabmeier-Pfistershammer K, et al. Malignant syphilis in a HIV infected patient. Sex Transm Dis 2015; 42: 223-225.

4. Pfohler C, Koerner R, von Muller L, et al. Lues maligna in a patient with unknown HIV infection. BMJ Case Rep 2011; 2011: bcr0520114221.

5. Tucker JD, Shah S, Jarell AD, et al. Lues maligna in early HIV infection case report and review of the literature. Sex Transm Dis 2009; 36: 512-514.
6. Vinay K, Kanwar AJ, Narang T, et al. Malignant syphilis. Int J Infect Dis 2013; 17: e930-e931.

7. Alves J, Antonio AM, Matos D, et al. Malignant lues in an immunocompetent patient. Int $J$ STD AIDS 2015; 26: 518-520.

8. Lejman K and Starzycki Z. Early malignant syphilis observed during infection and reinfection in the same patient. Br J Vener Dis 1978; 54: 278-282. 